\title{
Are radiological diagnostic centres ready to tackle COVID-19 pandemic? An Indian perspective
}

\author{
Kunal B Gala, Bharat M Gala1,2, Foram B Gala1,2,3 \\ Department of Radiodiagnosis, Tata Memorial Hospital, Homi Bhabha National Institute, Mumbai, 'Gala Imaging Centre, \\ ${ }^{2}$ Lifescan Imaging Centre, ${ }^{3}$ Department of Radiodiagnosis, B.J. Wadia Hospital, Mumbai, Maharashtra, India
}

Correspondence: Dr. Foram B Gala, Gala Imaging Centre, Malad, Mumbai, Maharashtra, India. B.J. Wadia Children's Hospital, Mumbai, Maharashtra, India.E-mail: drforamgala@gmail.com

\begin{abstract}
Corona virus disease 2019 (COVID-19) is caused by severe acute respiratory coronavirus 2 (SARS-CoV-2) and has been declared as pandemic. Its transmission is mainly by droplets and touching infected surfaces. Health care workers including personnel working at diagnostic centers are more prone to contact the disease through infected patients and hence various precautionary measures have to be implemented which has been discussed in this article. This manuscript shall brief about the preparedness by the diagnostic center in terms of the modification in the work flow, the precautions and protections to be taken by the personnel and patients, disinfection of the equipment and surfaces, and new norms of social distancing. This article will be addressing mainly to the diagnostic centers and the changes to be made as per their convenience.
\end{abstract}

Key words: COVID-19; diagnostic centers; health care workers

\section{Introduction}

Corona virus disease 2019 (COVID-19) is caused by severe acute respiratory coronavirus 2 (SARS-CoV-2) which causes pneumonia like symptoms in the patient. On 11 March 2020 this disease is labelled as pandemic by WHO.$^{[1]}$ It started in Wuhan city, Hubei province in China in December 2019 where people worked or stayed in and around the Huanan sea food wholesale market and most of the people developed severe respiratory distress or failure. Due to globalization, the virus spread across the globe and turned into pandemic. The number of people affected are increasing day by day across the globe and also in India. Since no specific medicines or vaccines are available for COVID-19,

\begin{tabular}{|l|l|}
\hline \multicolumn{2}{|c|}{ Access this article online } \\
\hline Quick Response Code: & \\
\cline { 1 - 2 } & Website: \\
\hline & www.ijri.org \\
\cline { 1 - 2 } & DOI: \\
\cline { 1 - 2 } & 10.4103/ijri.IJRI_466_20 \\
\hline
\end{tabular}

the patient isolation is most important way to curb the virus and prevent spread to others.

The COVID-19 infection is confirmed by identification of viral RNA by the reserve-transcriptase polymerase chain reaction (RT-PCR) and swab taken from nasal or oropharyngeal area. There is significant increase in the cases across India so availability of the bed in the hospital is difficult and thus crippling the health care system. In India, the private practice forms at least $60-70 \%$ of the health care system and medical personnel are at increasing risk of

This is an open access journal, and articles are distributed under the terms of the Creative Commons Attribution-NonCommercial-ShareAlike 4.0 License, which allows others to remix, tweak, and build upon the work non-commercially, as long as appropriate credit is given and the new creations are licensed under the identical terms.

For reprints contact: WKHLRPMedknow_reprints@wolterskluwer.com

Cite this article as: Gala KB, Gala BM, Gala FB. Are radiological diagnostic centres ready to tackle COVID-19 pandemic? An Indian perspective. Indian J Radiol Imaging 2021;31:S15-20.

Received: 12-Jun-2020 Accepted: 05-Jul-2020

Revised: 18-Jun-2020 Published: 23-Jan-2021 
contracting this disease or being carrier. ${ }^{[2]}$ It is extremely necessary to protect and prevent this novel virus affecting the health care personnel. In India, the radiology diagnostic center which are predominantly outpatient imaging centers form the basic health care facility to people. Thus, in this article, we will be briefing about the modification in the work flow, the precautions and protections that needs to be taken by the personnel and patients, disinfection of the equipment and surfaces, and new norms of social distancing. Since there are no guidelines either by any particular organization related to imaging centers, we would like to highlight these things in our article. People can modify as per their requirement to enhance protection of themselves as well as their staff.

\section{Transmission}

SARS CoV2 is highly contiguous virus and human to human transmission is by respiratory droplets, touching infected surfaces and aerosol transmission. ${ }^{[3]}$ When the droplets particles are $>5-10 \mathrm{um}$ in diameter, they are called as respiratory droplets, $<5 \mathrm{um}$ they are called as droplet nuclei. Droplet transmission occurs when the person is near infected person in close contact with $<1$ meter apart and ingests or inhales respiratory droplet. Touching the infected surfaces i.e., contact transmission occurs when a person touches mucosae or conjunctiva after touching a contaminated surface (known as "fomite"). Aerosol transmission occurs when the particles are $<5$ um and remain in the environment for much longer period and can travel $>1$ meter for example endotracheal intubation, tracheostomy suctioning, cardiopulmonary resuscitation etc. ${ }^{[4]}$ According to National institute of Health, SARS-CoV-2 is detected up to 3 hours in aerosols, up to 24 hours on the cupboard and up to 2-3 days on plastic and stainless steel. ${ }^{[5]}$ Since the patient is highly infective, it is paramount important to isolate the patient of COVID-19. This mode of transmission is important so as to educate the people and HCW staff regarding the COVID-19.

\section{Clinical features and testing}

In the initial phase of the infection, the person is asymptomatic and thus becomes most vulnerable to infect others. The intubation period of the virus is 4-5 days but can be as long as 14 days. ${ }^{[6]}$ There are many ways by which COVID -19 can present but the most common symptoms are fever, dry cough and tiredness. Other less common symptoms include aches and joint pains, sore throat, diarrhea, conjunctivitis, loss of taste or smell and rash on skin. Some of the serious symptoms which difficulty in breathing or shortness of breath, chest pain or loss of speech. ${ }^{[7]}$ In $80 \%$ of the infected person the infection is mild and can be managed with symptomatic treatment and to remain in isolation, other 15\% may have severe symptoms and require hospital admission and require oxygen and rest $5 \%$ are critical who may require ICU admission and ventilation.
There are two tests available to diagnose COVID-19. They are viral test and antibody test. The viral test is the identification of viral RNA by the reserve-transcriptase polymerase chain reaction (RT-PCR) and swab taken from nasal or oropharyngeal area of the infected person. This test will tell whether person is having active infection or not but the sensitivity of the test is just $30-60 \%$ at initial presentation ${ }^{[8]}$ while antibody test are serological test which detects IgG and IgM antigens and gives information if the person is infected in the past.

It is important to consider every patient walking into the diagnostic center as a potential COVID-19 positive and appropriate precautions need to be taken by doctors and staff.

\section{Diagnostic center}

Until date i.e., 29 the May, 2020, India already underwent 3 phases of lockdown i.e., from $25^{\text {th }}$ March 2020 to $14^{\text {th }}$ April 2020 (Lockdown 1.0) and from $15^{\text {th }}$ April 2020 to $3^{\text {rd }}$ May 2020 (Lockdown 2.0), $4^{\text {th }}$ May 2020 to $17^{\text {th }}$ May 2020 (Lockdown 3.0) and ongoing Lockdown 4.0 from $18^{\text {th }}$ May 2020 till date. Most of the diagnostic centers were open only for few hours with limited staff due to logistic issue like no public transportation. In cases of suspected COVID-19, patient was referred to high centers either government or private hospitals. This is the new era of COVID-19 prevention of this infection transmitting to health care workers is most important and the treatment of the people is equally important from COVID-19 and non COVID-19 disease. Health care workers (HCW) need to charge up to serve the people of the country in this pandemic. The government also gave notification to start private practice as the cases were increasing. So is it important to work with new norms, manage the work flow in the diagnostic imaging centers.

\section{Management of the work flow}

This is key thing in the management of patients. As most of the general population which is afraid of coming outside the house unless absolutely necessary. The cases which come are either emergency or semi-emergency cases and most of the elective cases are postponed.

- Indication of the procedure - Be it X-ray, USG, CT scan or MRI, the indication must be defined by the director or the chief doctor or doctor in charge of the center. For Ultrasound and CT guided procedures -there are recommendation by the Society of Interventional Radiology (SIR) regarding the acuity of the procedure which should be carried out. ${ }^{[9]}$ For aerosol generation procedure proper precaution needs to be taken

- Appointment (time specific) slots - This is most important for the safety of the patient, doctors and health care staff

- All appointments to be taken on phone. While taking appointment check for the complete name, 
age, sex, phone no., place of residence (to trace contact or containment area), chief complaints like fever, travel history, cough, breathlessness, COVID-19 test if done. If fever is present, then directly refer to fever OPD setup by the government

- Time slot depending on the examination-Different for different modality. Good Time gap between two patients. It depends upon the space i.e., availability of the waiting area rooms, number of examination rooms as in case of X-Ray, Ultrasound etc

- Allow only one relative with patient

- Discourage walk-in patient or give them appointment depending upon the schedule

- If more patients, maintain social distancing between them with space of atleast 1 meter between them

- Recommendation are no central air conditions (AC) should be on when either patient or suspected patient is in the clinic or in examination room. So best is to use stand one AC which should run on vent open mode ${ }^{[10]}$

- Natural ventilation with air flow of at least $160 \mathrm{~L} / \mathrm{s}$ per patient and Negative pressure rooms with 12 air changes per hour if available. ${ }^{[11]}$

- Staff education and meeting:

- Staff having cardiac or pulmonary disease or uncontrolled diabetes should be refrain from work.

- Staff should be working in rotation

- $\quad$ Staff needs to be educated regarding COVID-19 and its preventive measure

- Staff needs to be trained to do temperature monitoring and its importance, PPE, hand wash/ hand hygiene and social distancing

- Staff need to be trained to take detail history on phone so as to minimize the interaction and to give proper appointment so as to avoid overcrowding

- $\quad$ Staff must be educated not to sit in groups while having meals as maximum time of infection spread

- $\quad$ Staff need to learn donning and doffing of PPE kits

- Employer and employee need to be meet regularly virtually on the video conference so as to know the difficulties face and manage the situation in a better way.

\section{- Instruction to patients during appointment:}

- Tell the patients and relative to come with 3 ply surgical mask and gloves, if possible

- Tell patients to carry hand sanitizer:

- Tell the patients do not wait for report or tell them specific time when the report will be available. If email and mobile phone available can give soft copy reports. Films and/or CDs can be given after finishing the study so that relative do not come again.

- Things to do by the center:

- Temperature monitoring for all patients with infrared thermometer, if high temperature refers to fever clinic as setup by Govt
- $\quad$ Education for the staff regarding COVID-19

- Poster on walls regarding social distancing, hand hygiene, wearing mask

- Keep sanitizer at each door (inside as well as outside). Tell patient to sanitize before entering the examination room

- $\quad$ Give new pair of gloves to patients

- $\quad$ Give new 3-ply surgical mask to patients, if not there with patient

- Insurance for all health care staff

- Filled declaration form and informed written consent document needs to be obtained from the patient. This would be undertaking that patient understand the risk of getting infected by visiting the center during this pandemic and the examination is necessary at this point

- For the referral physician - They need to be updated the finding of the examination/test of the patient. If any findings are suspicious regarding this novel SARS-CoV-2 virus he should be informed and RT-PCR test should be carried out immediately without any delay.

\section{Personal protect equipment (PPE)}

There are various PPE available so it important to give adequate protection to all the health care workers, but at the same time there should be judicious use of the PPE at all the level.

All patients coming for routine diagnostic procedure like X-Ray, Ultrasound, CT scan or MRI must be considered positive unless they have COVID-19 negative report. However, since there is high false negative RT-PCR in COVID-19 testing its better to consider all patient coming to diagnostic center as positive.

- Outside the reception/triage area:

Person monitoring temperature with hand held infra-red thermometer should stand at the distance of 1 meter he is at low risk. ${ }^{[12]}$ So N95 with simple 3 ply surgical mask, gloves and shield.

\section{- Reception:}

- The person at the reception needs to ask basic questions like name of the patient and confirm the identity if the appointment is already taken

- If no appointment taken, to ask basic questions as mentioned above

- Consent to be taken for all patients as mentioned above. Obstetric consent form and referral form needs also to be taken for all pregnancy scan. These consent form need to be kept in the transparent polythene bag without touching it

- Digital payments would be ideal. If payments are made by cash, then should be collected in the sterile polythene bag, so that no one touches it.

Since the patient or the relative spend significant amount of time at the reception counter, they carry 
moderate risk. Since they are at moderate risk, N95 mask with FFP2, gloves and shield have to be given

- Technologist either for CT scan, X-Ray or MRI: While doing any form of examination for less than $45 \mathrm{~min}$, they are in moderate risk. So, in moderate risk, N95 mask, shield, non-sterile disposable gown and gloves need to be given

Doctor/physician: As compared to all other modalities, a radiologist is at highest risk while performing ultrasound examination as it's a closed small space with close contact with patient. So, he comes in moderate risk while doing ultrasound, so N95 mask, gloves, non-sterile disposable gown and shield are sufficient. While reporting X-ray, CT scan and MRI scan the doctor is either not in contact or in contact for brief time while taking history

While doing any invasive procedure like Fine needle aspiration cytology (FNAC), Core needle biopsy, paracentesis etc., Surgical scrubs, with N95 mask, shield or eye protection goggles and are required. Full PPE kits is reserved for COVID positive patient. Full PPE kit which include caps, protective goggle or face shield, N95 masks, protective clothing, latex gloves, shoe covers and hand hygiene. Ideally, they should be referred to designated center. It is important to teach all the staff the importance of donning and doffing the PPE kit

Cleaning staff: All the cleaning staff comes in the moderate risk, so they need to wear N95 mask, non-sterile disposable gown, shield or goggles along with heavy duty gloves. They need to be protected from the corrosiveness of the chemical agents used for cleaning.

- Transport staff: They are in same risk as cleaning staff which comes under moderate risk

To increase the effectiveness of the N95 mask, All India Institute of Medical Science (AIIMS) has published standard operating procedure for extended use of these masks. As per these SOP every HCW is given 5 N95 mask and 5 paper envelop bag, 4 mask for use and 1 kept as reserve. Label each mask and bag from 1 to 5 . On Day 1, the HCW wears Mask no 1. After the days use this mask is not discarded instead kept in the paper bag no 1 and it is allowed to dry for 4 days. Similarly, on day 2, mask No. 2 is used and is done the same way as mask no 1 . These are done for mask 3 and 4 . On the $5^{\text {th }}$ day again, use mask no. 1 . N95 are discarded after 5 uses. So these will work for 20 days. These helps to prevent the shortage of N95 and increase the effectiveness of N95. Further we use 3 ply surgical mask over N95 to increase the effectiveness. The 3-ply surgical mask is discarded at the of days works. ${ }^{[13]}$
Cleaning and sanitization of radiology clinic

Cleaning and sanitization are most important step during this pandemic COVID-19 infection to prevent transmission amongst the HCW.

\section{Floor Disinfectant:}

- Mopping of the floor should be carried out twice a day, depending on how many patients visit the center. It is generally done before the start of day work and in the end of days' work. The mopping of all the areas needs to be done when no one is around so as to prevent infection. Mopping of the floor is with bleach. Bleach contains $5.25 \%$ sodium hypochlorite, hence proper dilution needs to be done as below:

- 1 part of bleach in 99 parts of water - for general household cleaning

- 1 part of bleach in 49 parts of water - surface contaminated with vomitus, excreta and secretion

- 1 part of bleach in 4 parts of water - for surface contaminated with blood and blood products spillage. ${ }^{[14]}$

- Wiping all frequency touched areas with disinfectant once daily. For e.g., Light switches, seat backs, elevator buttons, arm rests, door knobs, keyboard, tables, telephones with absorbable cloth soaked with $1 \%$ sodium hypochlorite solution or with $70 \%$ isopropyl alcohol or ethyl alcohol.

- Wiping all the walls up to 3 meters in height.

- Any aerosol generating equipment should not be used.

- Cleaning of toilets, toilet pots, seats, lids etc. should be done with $1 \%$ sodium hypochlorite for 3 to 4 times a day.

- Linen, curtains and bed sheets should be cleaned with washing detergent or disinfectant in water at $700 \mathrm{C}$ for $25 \mathrm{~min}$. If low temperature is used than used appropriate chemical solution. ${ }^{[14]}$

Equipment disinfectant: All non-essential items and things needs to be removed every room. These must be kept in the cupboard or place where it's not been visited by people. All the monitors, keyboard, mouse, chairs, console need to be covered with plastic polythene. If not possible all the objects kept open needs to be sanitized.

- X-Ray - On the X-ray tube and the cassette needs to be covered by plastic polyethene covered daily or per patient (depending on the indication) and need to be discarded at the end of day or if any suspected patient had undergone the test [Figure 1]

- Cleaning of the cassette- outer slide of the cassette needs to be cleaned after each X-Ray and before entering the Computed Radiography (CR) system. This cleaning must be done with sodium hypochlorite solution using cotton swab

- $\quad$ Cleaning the table or stand-Cleaning of table, stand needs to be done with $70 \%$ of ethyl alcohol at the end of day work. If any person suspected than cleaning and sanitization needs to be done. 


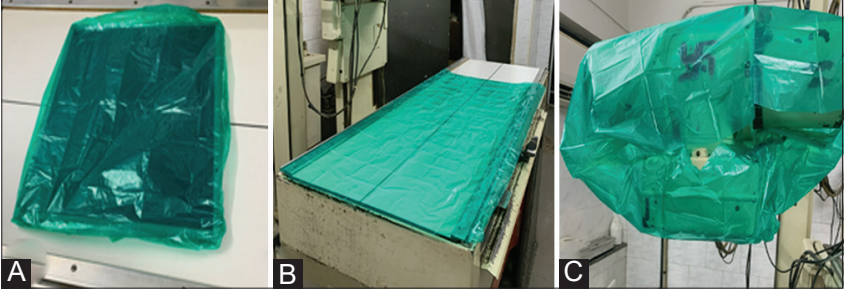

Figure 1 (A-C): X-ray cassette (A), X-ray table $(B)$ and X-ray tube $(C)$ covered by plastic polyethene when suspected or proven COVID-19 patient

- Ultrasound: Transmission in COVID -19 is by surfaces so the surface in coming in contact are Transducer and cable of the transducer and others like keyboard, tract ball etc., of the ultrasound machine. These have to be cleaned after each procedure or alternately one can cover the Ultrasound probe with the plastic polythene [Figure 2] and discard after every patient. Excess of Ultrasound gel needs to be wiped out since its on most infective surface. Cleaning of the transducer is by $70 \%$ alcohol-based solution or whichever is approved by the company. Even cleaning of keyboards, desktop, edges etc., can be cleaned with $70 \%$ alcohol-based solution. Alternately, the transducer of the ultrasound probe can be covered by glove which is cheapest or camera cover. These are must while doing any ultrasound guided procedures ${ }^{[10]}$

- CT scan: If the patient is suspected patient is scanned, then CT scan table couch is covered with plastic disposable sheets prior to scanning the patient [Figure 3]. After the scan plastic disposable sheets are discarded and the surface is cleaned with $70 \%$ ethyl alcohol. The floor of the CT scan room is cleaned as mentioned above. While doing routine CT scan, before the start of the day cleaning of the couch and floor is must and also at the end of the day

- MRI: Guidelines have been laid by ACR regarding the prevention of transmission of infection. MRI cleaning needs to be done when patient either suspected or known COVID-19 has MRI scan done. The cleaning of the couch, and equipment needs to be done in the clockwise manner, linear, top to bottom for all visible surfaces. There is downtime of 60 minutes followed by the cleaning as described above

A soft cloth should be dipped in the disinfectant to wipe the surface of equipment. When using ethanol, dry the surface in air, however when using a chlorine containing disinfectant, after completing disinfection, use a soft cloth dipped in water to clean residual chlorine disinfectant on the surface of device, then dry in air or wipe dry with dry soft cloth

- Never use flammable or explosion-prone disinfectant sprays as steam may cause fire, fatal injury, personal injury. Also, vapors may enter the equipment causing short circuit, its damage or corrosion

- Cleaning materials should be disposed

- If mats, sandbags or earphone sponge pads are found

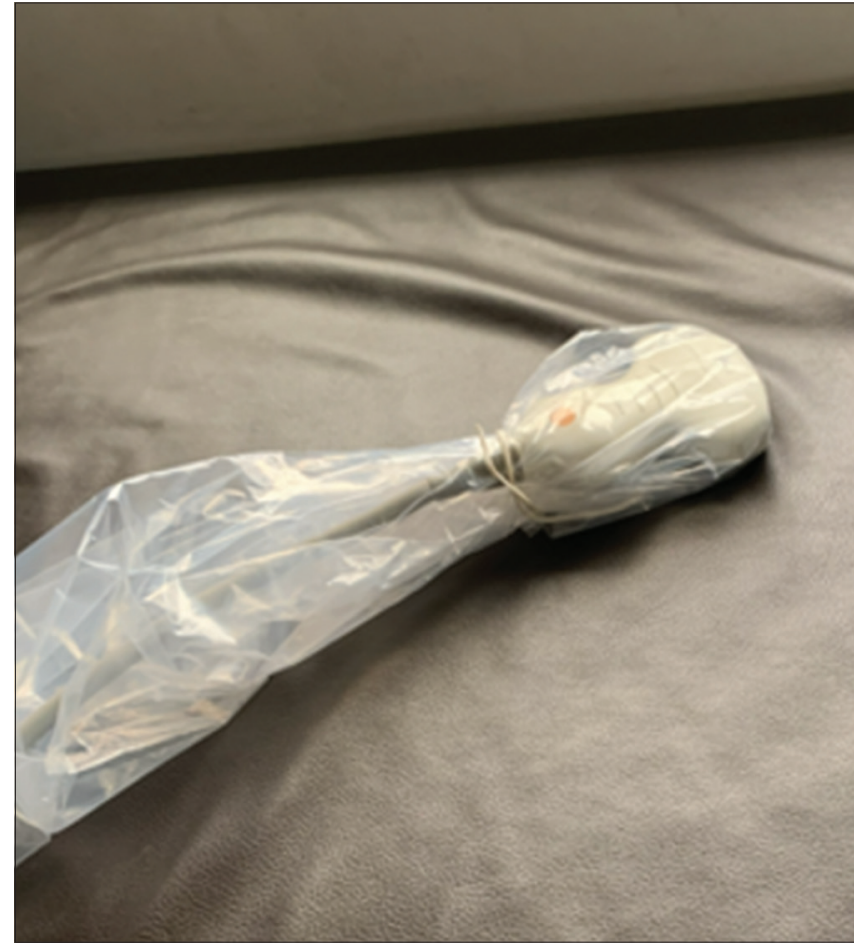

Figure 2: Ultrasound probe is covered plastic polyethene when suspected or proven COVID-19 patient

damaged, do not continue using them. They need to be replaced

- If cracks or damage to coils or cables see, then do not continue to use

If the patient is wearing the surgical mask which has metallic strip it needs to be changed. The staff when wearing PPE must ensure no metallic strip, staples etc., are present. If so, can remove it and replace with tape. ${ }^{[15]}$

\section{Discarding the medical waste:}

- Discard PPE in double bagged biohazard bag which should be sealed and labeled

- Discard gloves, Masks in the same way as PPE kit

- Discard all the mops, cloth wipes after use into the biohazard bags.

\section{Future prospective:}

- Virtual tele-conference with the referring physician and education regarding the imaging findings

- Virtual meeting between radiologist groups to know further regarding COVID-19 infection

- Guidelines from the Indian society.

\section{Conclusion}

Diagnostic radiology centers in India are the outpatient imaging centers which gives high quality health care facility to people. Improving and modifying the work flow, precautions and protection needed by the personnel and patients, disinfection of the equipment and surfaces, 


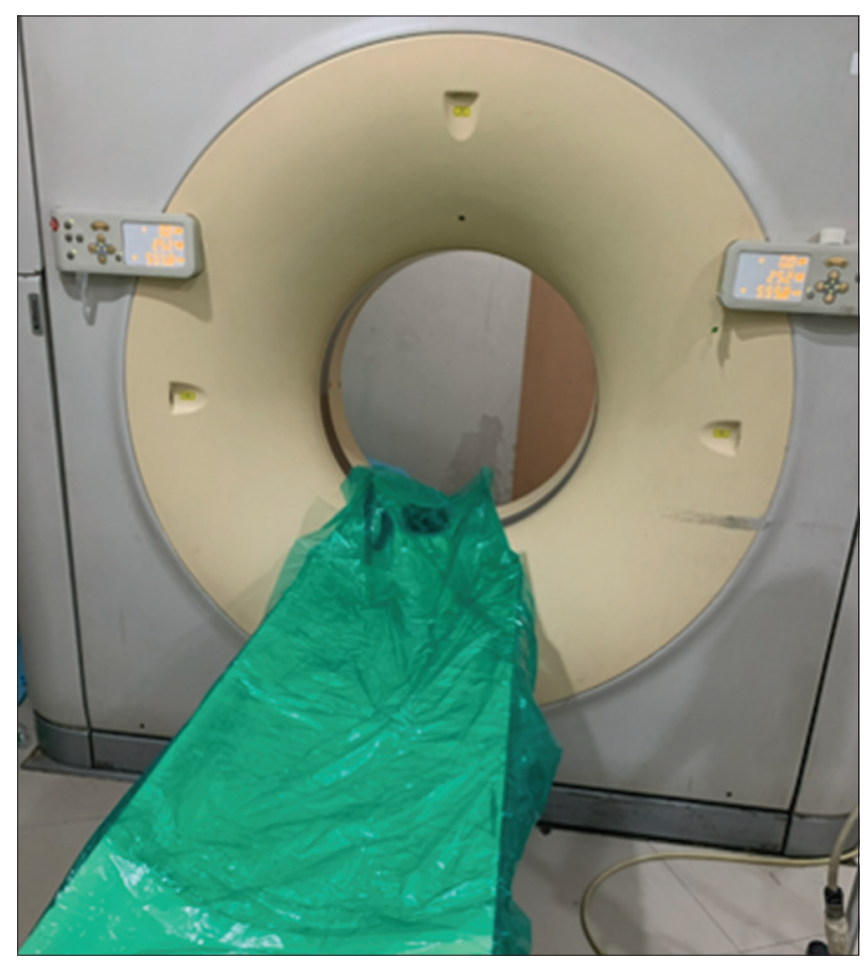

Figure 3: CT scan couch is covered with plastic polyethene when suspected or proven COVID-19 patient

and new norms of social distancing. These are new things which the diagnostic center must follow so that it's "better to be safe" and thus aid in preventing cross transmission of infection in the COVID-19 pandemic.

\section{Financial support and sponsorship}

Nil.

\section{Conflicts of interest}

There are no conflicts of interest.

\section{References}

1. WHO Director-General's opening remarks at the media briefing on COVID-19.
2. Thayyil J, Jeeja MC. Issues of creating a new cadre of doctors for rural India. Int J Med Public Heal 2013;3:8.

3. Zanardo M, Martini C, Monti CB, Cattaneo F, Ciaralli C, Cornacchione $\mathrm{P}$, et al. Management of patients with suspected or confirmed COVID-19, in the radiology department. Radiography. 2020;26:364-8.

4. Available from: https://www.who.int/news-room/commentaries/ detail/modes-of-transmission-of-virus-causing-covid-19implications-for-ipc-precaution-recommendations.First published on 29 March 2020, updated on 9 July based on updated scientific evidence.

5. New coronavirus stable for hours on surfaces SARS-CoV-2 stability similar to original SARS virus; 2020. Available from: https://www. nih.gov/ news-events/news-releases/new-coronavirus-stablehours-surfaces. [Last accessed on 2020 Mar 17].

6. Li Q, Guan X, Wu P, Wang X, Zhou L, Tong Y, et al. Early transmission dynamics in wuhan, china, of novel coronavirusinfected pneumonia. N Engl J Med. 2020;382:1199-207.

7. Available from: https://www.cdc.gov/coronavirus/2019-ncov/ symptoms-testing/symptoms.html, https://www.who.int/healthtopics/coronavirus\#tab=tab_3. Updated June 24, 2020.

8. Zhao Y, Xiang C, Wang S, Peng C, Zou Q, Hu J. Radiology department strategies to protect radiologic technologists against COVID19: Experience from Wuhan. Eur J Radiol. 2020;127:108996. doi: 10.1016/j.ejrad.2020.108996.

9. Available from: https://www.sirweb.org/practice-resources/ toolkits/covid-19-toolkit/covid-19-postponed-procedures/ updated April 27,2020.

10. Khurana A, Sharma KA, Bachani S, Sahi G, Bhatt RK, Sahani B, et al. SFM India oriented guidelines for ultrasound establishments during the COVID 19 pandemic. J Fetal Med. 2020:1-7. doi: 10.1007/ s40556-020-00254-7.

11. Available from: https://ncdc.gov.in/WriteReadData/ 1892s/53436598731586345131.pdf. April 3, 2020.

12. Ong SWX, Tan YK, Chia PY, Lee TH, Ng OT, Wong MSY, et al. Air, Surface environmental, and personal protective equipment contamination by severe acute respiratory syndrome coronavirus 2 (SARS-CoV-2) from a symptomatic patient. JAMA. 2020;323:1610-2.

13. Available from: https://www.aiims.edu/images/pdf/notice/ SOP_N95_09_04_20.pdf. [Last accessed on 2020 Apr 08].

14. Available from: https://www.mohfw.gov.in/pdf/ DGSOrder04of2020.pdf. [Last accessed on 2020 Mar 20].

15. Available from: https://www.acr.org/Clinical-Resources/ Radiology-Safety/MR-Safety/COVID-19-and-MR-Use. 